Miami Nature Biotechnology Short Reports

TheScientificWorld (2001) 1(S3), 76SR

ISSN 1532-2246; DOI 10.1100/TSW.2001.138

\title{
THE INSULIN SIGNALING PATHWAY AND AGING IN DROSOPHILA
}

\author{
Linda Partridge
}

Department of Biology, University College London, Wolfson House, 4 Stephenson Way, London NW1 2HE, UK

ucbhlop@ucl.ac.uk

Model organisms such as yeast, the nematode worm C. elegans and the fruit fly Drosophila are providing useful insights into the aging process. For information gathered from these organisms to be useful medically, it is important that mechanism of aging be conserved during evolution.

In the nematode worm C. elegans, mutation of genes encoding components of the insulin/Insulinlike Growth Factor (IGF) signaling pathway extends the lifespan of the adult worm. They also confer resistance to environmental stresses such as heat and oxidation, and are associated with increased levels of antioxidant defenses. These mutations were discovered because they also control entry to an alternative route of development, to a growth-arrested, non-feeding, fat-storing, stress-resistant dauer larva that is produced in response to crowding. Thus, the extension of adult lifespan by these mutations could be a peculiarity of C. elegans, resulting from the pathway's function in the regulation of the dauer developmental route.

We have examined the effects on aging of mutations in genes in the homologous pathway in another model organism, Drosophila. Mutants have been made in several of the genes in the insulin pathway, to study effects on growth during the pre-adult period. Over-expression of several components of the pathway increases growth rate and final size. We find that a mutation in one of these genes, chico, a homologue of the vertebrate insulin receptor substrates 1-4, increases mean and maximum lifespan of the fly. Unlike the findings in C. elegans, we find no association between mutations in the pathway and resistance to environmental stress. Nor did we find that elevated antioxidant defences, dwarfism, high lipid content or reduced reproductive rate, all associated with in chico, played any role in extension of lifespan. Thus the role of the insulin/IGF signaling pathway in regulating lifespan is evolutionary conserved, but many of the other conserved effects of the pathway seem not to be causal in extension of lifespan.

We tested the hypothesis that insulin/IGF signaling mediates the extension of lifespan by caloric restriction. If insulin/IGF mutants are already somewhat calorically restricted by their genotype, then we would predict that their lifespan would be maximal at a higher food level than would that of controls, and that the mutants would be more susceptible to the effects of starvation. Both of these predictions were confirmed, demonstrating that in Drosophila lifespan extension by caloric restriction is mediated by insulin/IGF signaling. 


\section{REFERENCES.}

1. Sgrò, C. and Partridge, L. (1999) Science, 286, 2521-2524

2. $\quad$ Partridge, L., Prowse, N., and Pignatelli, P. (1999) Proc. R. Soc. Lond. B 266, 255-261

3. Rogina, B., Vaupel, J.W., Partridge, L., and Helfand, S.L. (1998) Curr. Biol. 8, 475-478

4. $\quad$ Chapman, T. and Partridge, L. (1996) Proc. R. Soc. Lond. B 263, 755-759

5. $\quad$ Chapman, T., Liddle, L.F., Kalb, J.M., Wolfner, M.F., and Partridge, L. (1995) Nature 373, 241-244

6. $\quad$ Partridge, L. and Barton, N.H. (1993) Nature 362, 305-311 

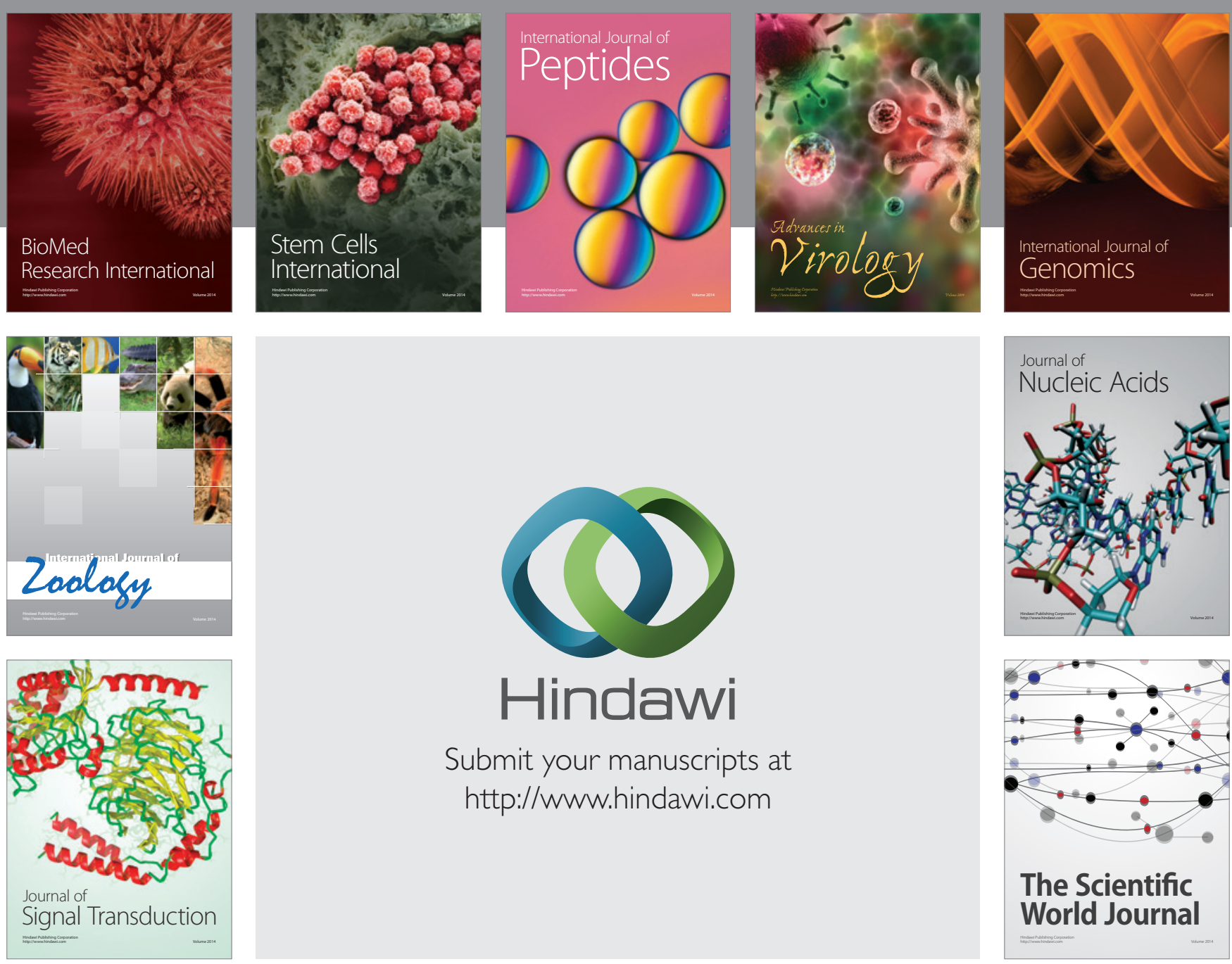

Submit your manuscripts at

http://www.hindawi.com
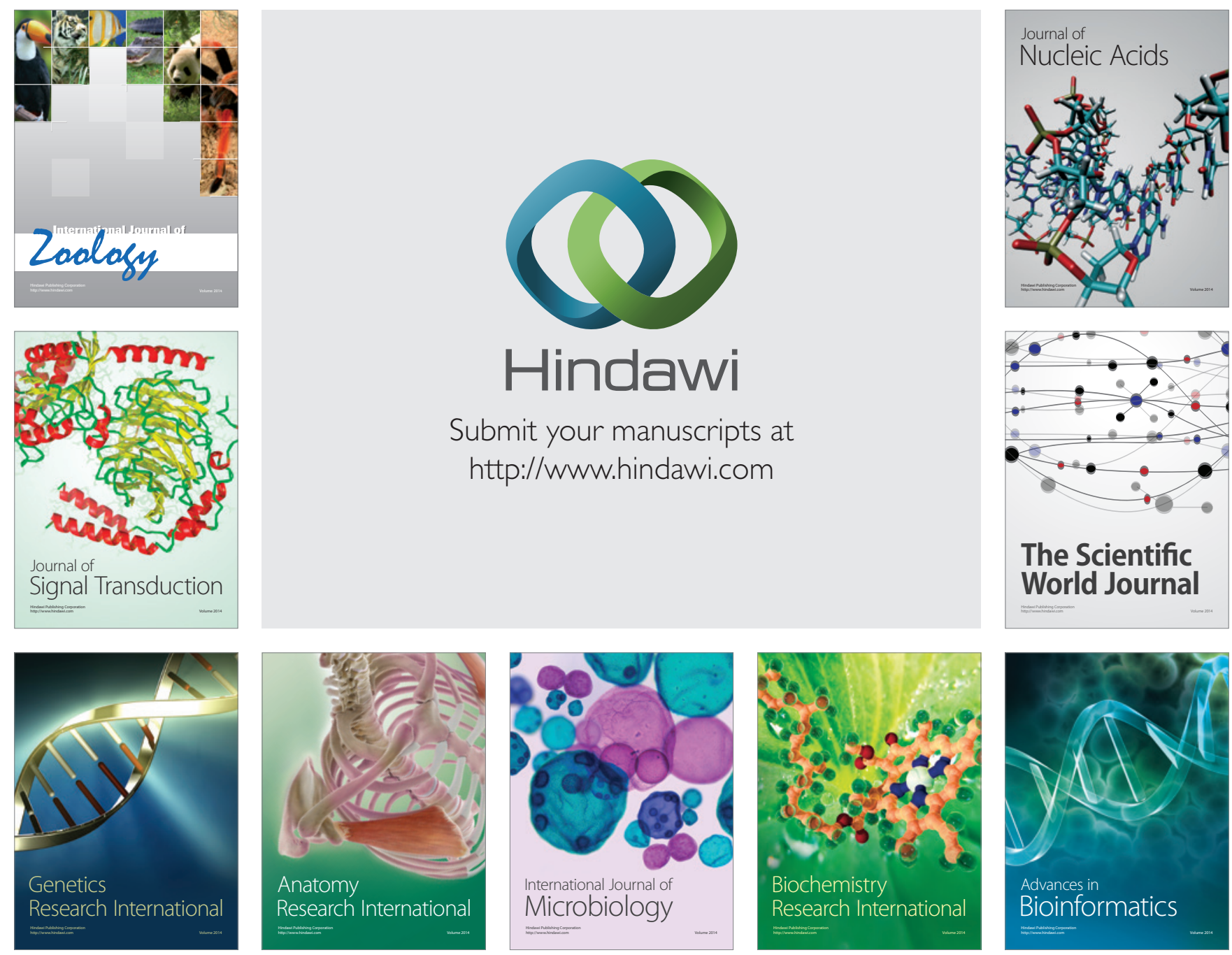

The Scientific World Journal
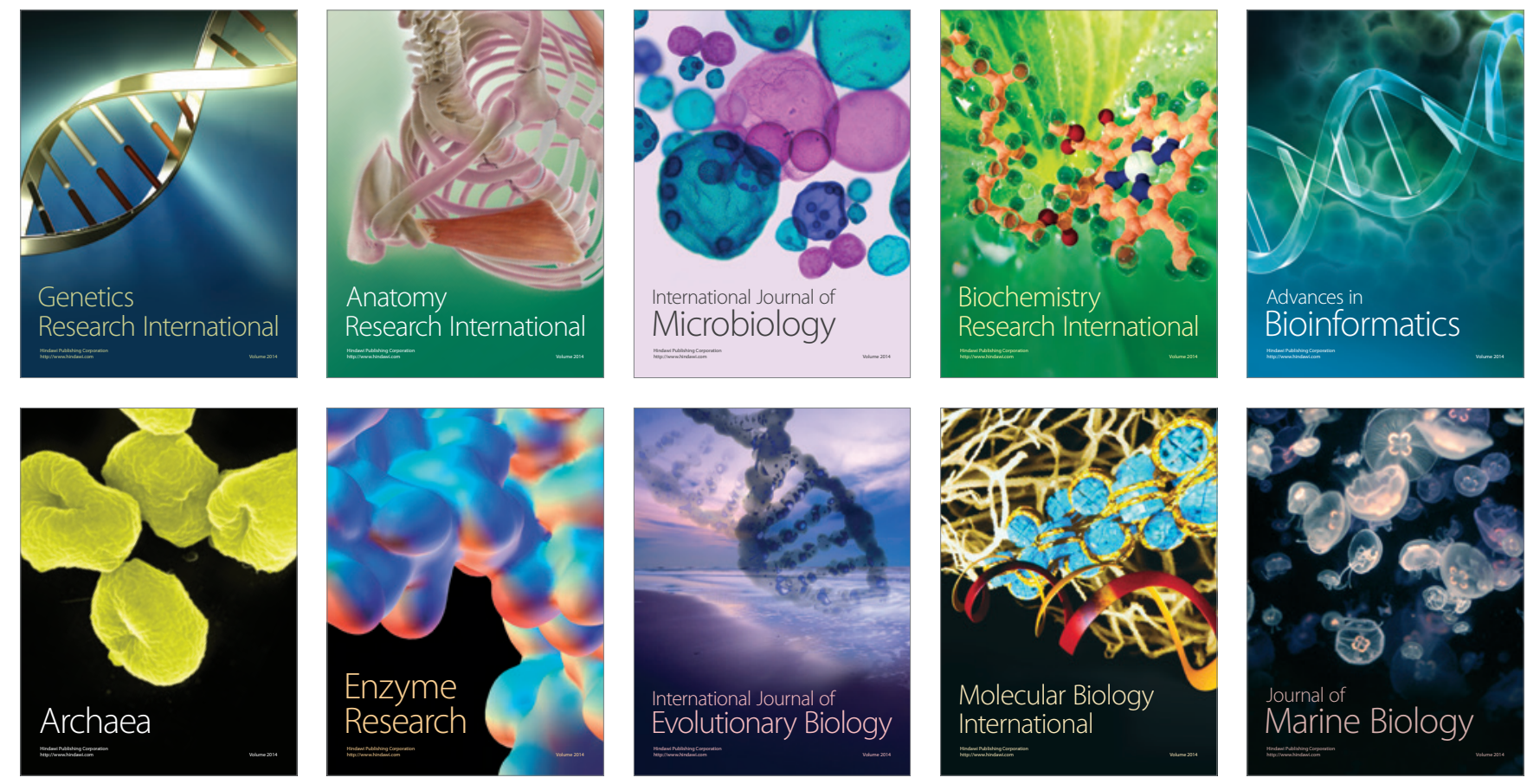